\title{
Histamine in psychiatry: promethazine as a sedative anticholinergic
}

\author{
John Cookson
}

\begin{abstract}
SUMMARY
The author reflects on discoveries over the course of a century concerning histamine as a potent chemical signal and neurotransmitter, the development of antihistamines, including promethazine, and chlorpromazine from a common precursor, and the recognition of a major brain pathway involving histamine. Although chlorpromazine has been succeeded by numerous other antipsychotics, promethazine remains the antihistamine recommended for sedation in acutely disturbed patients, largely because it is potently anticholinergic at atropinic muscarinic receptors and therefore anti-Parkinsonian: this means it is also useful in combination with older antipsychotics such as haloperidol.
\end{abstract}

\section{DECLARATION OF INTEREST}

None.

\section{KEYWORDS}

Histamine; antihistamines; tranquillisation; antipsychotics; history.

Histamine is a small positively charged molecule derived from the amino acid histidine, originating from ergot, the fungal putrefaction of protein in rye (Fig. 1). It was identified as biologically active by one of the founding fathers of British pharmacology, Henry Dale: working with Patrick Laidlaw in the laboratories of Sir Henry Wellcome in London, they described all its main actions - except that of stimulating gastric acid secretion (Dale 1910). They very presciently compared its effect in lowering blood pressure to that of anaphylactic 'shock'. Histamine was suspected to be released in allergic conditions: urticaria, hay fever, bronchospasm and anaphylaxis. And drugs that would antagonise histamine had obvious therapeutic potential.

\section{The first antihistamines}

Daniel Bovet (1907-1992) led in the search for antihistaminics, working first in the therapeutic chemistry laboratory at the Pasteur Institute in Paris (strongly influenced by the ideas of Claude Bernard and Louis Pasteur). There he met Filomena Nitti, daughter of a former prime minister of Italy. They married in 1938 and she became her husband's lifelong co-worker. They moved in 1947 to the Institute of Health in Rome. In 1957 he was awarded a Nobel Prize for his work in developing drugs 'blocking the effects of certain substances occurring in the body, especially in its blood vessels and skeletal muscles' (Oliverio 1994). He and his research student Marianne Staub introduced the first antihistamine in 1937, developed by altering the structures of drugs found to block known transmitters - acetylcholine and adrenaline - such as atropine. Their compound, called 929F, counteracted the actions of histamine on smooth muscle and reduced anaphylactic shock; however, it was too toxic for clinical use.

\section{The synthesis of promethazine}

The synthesis of promethazine (Box 1) was first reported in 1944 by Dr Henry Gilman and David Stanley, chemists at Iowa State College, working on phenothiazines in a search for antimalarials. The antihistamine properties of promethazine (phenergan) were discovered in France in 1946 by Halpern, who was at the French National Centre for Scientific Research in Paris. This was the most potent of a series of antihistamines that were derivatives of phenothiazine. In the 1940s academic laboratories and the pharmaceutical industry strove to discover new and safer antihistamines, with such success that more than 50 were synthesised by 1965 (Dripps 1965).

The sedative properties of promethazine were studied by the French-Vietnamese surgeon-anaesthetist and pioneer-explorer Henri Laborit. Between 1948 and 1952 he developed what he called his 'lytic cocktail', intended to reduce the need for inhaled anaesthetic agents and to combat surgical 'shock' and post-operative vomiting. It contained initially barbiturates, promethazine and opioids such as pethidine. 'Lytic' implied loosening or relaxing (Valenstein 2002).
CLINICAL REFLECTION
John Cookson, FRCPsych, FRCP, is a consultant in general adult psychiatry for the Royal London Hospita and East London NHS Foundation Trust. He trained in physiology and pharmacology at the University of Oxford and he has a career-long interest in psychopharmacology. His duties have included work in psychiatric intensive care units since 1988 He has co-authored two editions of Use of Drugs in Psychiatry, published by Gaskell.

Correspondence: Dr John Cookson, Tower Hamlets Centre for Mental Health, Mile End Hospital, Bancroft Road, London E1 4DG, UK. Email: john.cookson1@nhs.net

First received 12 Mar 2019

Accepted 25 Mar 2019

Copyright and usage (C) The Royal College of Psychiatrists 2019 
<smiles>N[C@@H](Cc1c[nH]cn1)C(=O)O</smiles>

Promethazine<smiles>CC(CN1c2ccccc2Sc2ccccc21)N(C)C</smiles>

Histamine<smiles>CCC(=O)c1c[nH]cc1CCN</smiles>

Chlorpromazine<smiles>CN(C)CCCN1c2ccccc2Sc2ccc(Cl)cc21</smiles>

The structure of histidine, histamine, promethazine and chlorpromazine, and conversion of histidine to histamine (imidazolyl ethylamine) by histidine decarboxylase.

\section{BOX 1 Pharmacokinetics of promethazine}

Oral promethazine is almost completely absorbed from the gut and metabolised by hydroxylation (involving the hepatic enzyme CYP 2D6) and sulphoxidation in the liver, leading to a bioavailability of $25 \%$ and a peak concentration at 2-4 $\mathrm{h}$. The peak is at $2 \mathrm{~h}$ after intramuscular (IM) administration. The elimination half-life is $12-15 \mathrm{~h}$.

Atropinic plants and drugs (hyoscine (scopolamine) and atropine from henbane and nightshades) had long been used for their calming effects in psychiatric settings but were associated with toxicity (Shorter 1997). Psychiatrists began to investigate antihistamines from 1943, and promethazine was used in sleep therapy for agitation (Guiraud 1950; Healy 2002).

\section{Neuroleptanalgesia}

Further phenothiazines were synthesised by Paul Charpentier of Rhône-Poulenc (now Aventis) in Paris cooperating with academic laboratories (Halpern 1948). In 1950 Charpentier synthesised chlorpromazine as a variant of promethazine, and his associated pharmacologist Simone Courvoisier recognised its more diverse range of actions in the laboratory. Laborit described the novel effect of adding chlorpromazine to his cocktail as 'calm without sleep'. The combination was later called 'neuroleptanalgesia'. He encouraged psychiatrists to explore the drug. The introduction of chlorpromazine by psychiatrists Delay and Deniker in 1952 represented something 'very different' and the drug was also associated with Parkinsonian side-effects, giving rise later to the name 'neuroleptic' - literally meaning seizing the neuron - by Delay in 1955.

However, Henri Laborit's suggestion for using chlorpromazine in premedication for anaesthesia was by 1965 outdated. It did not counteract surgical shock but produced arterial hypotension and its sedative and anti-emetic properties could be achieved with other agents if necessary (Dripps 1965).

\section{Histamine and antihistamines}

Histamine is stored predominantly in mast cell granules (Riley 1953) and in basophils. After their discovery of immunoglobin $\mathrm{E}$ (IgE) in 1966, Kimishige Ishizaka in Denver found IgE binding sites on basophils and mast cells and that their aggregation by anti-IgE on basophils caused them to release histamine and a slow-reacting substance of anaphylaxis (SRS-A), later called leukotriene (Tomioka 1971), during allergic reactions. Antihistamines were confirmed to be useful in controlling these.

It became known that certain drugs lower blood pressure by releasing histamine (Schachter 1952); these include morphine, pethidine, atropine, certain muscle relaxants, antibiotics and quinine. 


\section{The tuberomammillary nucleus (TMN)}

The sedative effect of antihistamines indicated that histamine must have a role in the brain, and in 1957 histamine was identified within the brain. But it was not until much later, in 1984, that the main pathway was demonstrated, originating from approximately 64000 histamine-producing neurons in the tuberomammillary nucleus (TMN) near the mammillary bodies behind the hypothalamus (Box 2) (see Haas 2008). The TMN projects to diffuse areas of the forebrain, including the principal cells in the cerebral cortex, and is part of the reticular activating system. It is activated by the neighbouring orexin-containing neurons of the lateral hypothalamus during wakefulness and not during sleep. The TMN neurons express orexin-2 receptors. Furthermore, the histamine neurons project to other areas involved in wakefulness, such as the noradrenergic nucleus locus coeruleus, the cholinergic nuclei of the brainstem, and the dopamine neurons. Antihistamines block histamine actions in these sites. The TMN has been described as the first violin of the orchestra of cerebral arousal conducted by the orexin-containing neurons of the dorsolateral hypothalamus.

When activated, the TMN neurons stimulate $\mathrm{H}_{1}$ receptors in all the major parts of the brain, posterior pituitary and spinal cord. They increase arousal in the sleep-wake cycle, have roles in fluid balance, feeding, control of body temperature and the cardiovascular system, and release stress hormones from the pituitary.

BOX 2 Subtypes of brain histamine receptors and antihistamines

- Three types of histamine receptor are now recognised in the brain:

- $\mathrm{H}_{1}$, post-synaptic

- $\mathrm{H}_{2}$, mainly post-synaptic (also involved in gastric acid secretion)

- $\mathrm{H}_{3}$, largely presynaptic autoreceptors reducing the firing of tuberomammillary nucleus (TMN) neurons

- Newer $\mathrm{H}_{1}$ blockers were designed to be excluded by the blood-brain barrier and are therefore non-sedative (e.g. cetirizine, loratadine)

- $\mathrm{H}_{2}$ blockers were developed by Sir James Black (who received a Nobel Prize for his work) and treat peptic ulcer (e.g. cimetidine, ranitidine)

- $\mathrm{H}_{3}$ blockers have been used experimentally

- Histamine receptors are all metabotropic receptors; the second messenger for $\mathrm{H}_{1}$ is phospholipase- $\mathrm{C}$, affecting inositol and calcium release

- To add to the complexity, these receptors may be 'constitutively' active, meaning that inverse agonism is also a possibility

\section{The pharmacological activity of promethazine}

Perhaps reflecting its origin from compounds blocking the actions of other biogenic amines, promethazine has broad pharmacological activity. As well as being a antihistamine, it has significant atropinic effects (Halpern 1948).

Other actions include local anaesthetic effects stronger than procaine (blocking sodium channels), ictogenic effects (lowering the seizure threshold), antiemetic effects and blocking the HERG-encoded $\mathrm{I}_{\mathrm{Kr}}$ potassium channel in heart muscle fibres, thus prolonging the QT interval - although there is little evidence for it causing ventricular dysrhythmia. In higher doses it causes delirium. This was found in $31 \%$ of people reported to be taking 250 mg daily, and in a greater proportion of those on higher doses. (Page 2009). Perhaps being regarded as a safe sedative-hypnotic, it has been widely used in remedies for children, but life-threatening adverse events of promethazine in children (respiratory depression, cardiac arrest, seizures) led to a Food and Drug Administration black box warning being added to the labelling in the USA in 2004.

In terms of relative potency in blocking histamine $\mathrm{H}_{1}$ receptors and acetyl choline muscarinic receptors, promethazine is the most potently anticholinergic of the antihistamines (Kubo 1987). It is very much weaker in blocking dopamine receptors and is not effective in schizophrenia.

\section{Conclusions}

In 2016 promethazine reached the pinnacle of its fame in psychiatry when it was endorsed by National Institute for Health and Care Excellence (NICE) guidelines as one of the best-evidenced treatments for the management of violence, in combination with haloperidol (Cookson 2018). This apparent benefit is the result of a combination of sedative and antiParkinsonian (anticholinergic) effects - counteracting the potential side-effects of haloperidol, which is itself very efficacious for agitation in psychosis.

The profound importance of chlorpromazine in the history of psychiatry remains beyond dispute and promethazine, despite its limitations in terms of antipsychotic properties and its sedative sideeffects, which restrict its use as an anti-allergic medication, still has a useful role in psychiatry. Modern rapid tranquillisation aims to calm without sedation and - ironically - uses antipsychotics as Laborit did, but usually avoids the need for an anaesthetist.

\section{Acknowledgements}

I am grateful to Dr Jonathan Pimm for assistance on this manuscript. 


\section{References}

Cookson J (2018) Rapid tranquillisation: the science and advice. BJPsych Advances, 24: 346-58.

Dale HH, Laidlaw PP (1910) The physiological action of $\beta$-iminazolylethylamine. British Journal of Physiology, 41: 318-44.

Dripps RD (1965) Preanesthetic medication. In The Pharmacological Basis of Therapeutics (3rd edn) (eds LS Goodman, A Gilman): 57-60. Macmillan.

Guiraud P, David C (1950) Traitement de l'agitation motrice par un antihistamininique (R3277P). Comptes Rendues du Congrès Medicale des Médecins Aliénistes et Neurologues de Langue Française, 8 : 599-602.

Haas HL, Sergeeva OA, Selbach 0 (2008) Histamine in the nervous system. Physiological Reviews, 88: 1183-241.

Halpern BN, Hamburger J (1948) A new synthetic anti-histamine substance derived from phenothiazine (phenergan, 3,277 R.P.). Canadian Medical Association Journal, 59: 322-6.

Healy D (2002) The Creation of Psychopharmacology. Harvard University Press.
Kubo N, Shirakawa O, Kuno T, et al (1987) Antimuscarinic effects of antihistamines: quantitative evaluation by receptor-binding assay. Japanese Journal of Pharmacology, 43: 277-82.

Oliverio A (1994) Daniel Bovet, 23 March 1907 - 8 April 1992 Biographical Memoirs of Fellows of the Royal Society, 39: 61-70.

Page CB, Duffull SB, Whyte IM, et al (2009) Promethazine overdose: clinical effects, predicting delirium and the effect of charcoal. Quarterly Journal of Medicine, 102: 123-31.

Riley JF, West GB (1953) The presence of histamine in tissue mast cells. Journal of Physiology, 120: 528-37.

Schachter M (1952) The release of histamine by pethidine, atropine, quinine, and other drugs. British Journal of Pharmacology and Chemotherapy, 7: $646-54$.

Shorter E (1997) A History of Psychiatry: From the Age of the Asylum to the Era of Prozac. John Wiley \& Sons.

Tomioka H, Ishizaka K (1971) Mechanisms of passive sensitization. II. Presence of receptors for $\mathrm{IgE}$ on monkey mast cells. Journal of Immunology, 107: 971-8.

Valenstein ES (2002) Blaming the Brain: The Truth about Drugs and Mental Health. Free Press. 